\title{
A ClÊnCIA da Medição - I
}

\section{Filomena Camões*}

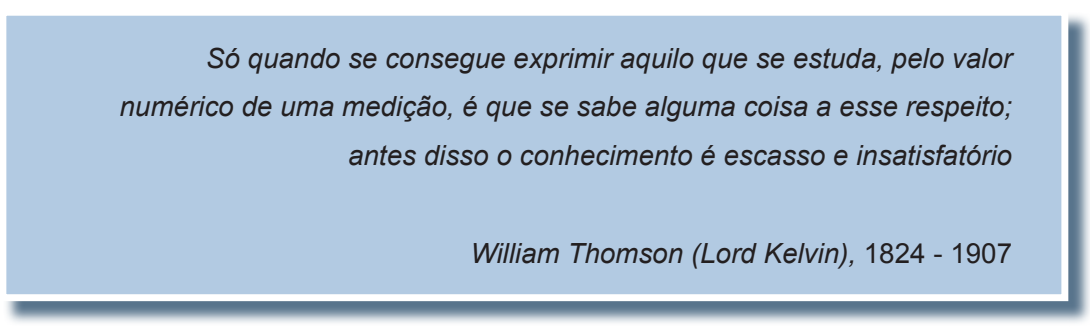

\section{Medir A DISTÂNCIA Às ESTRELAS}

Já lá vão uns anos, certa manhã a Rádio transmitia uma reportagem da visita do Sr. Ministro da Ciência, da altura, a uma escola básica e/ou secundária do norte do País, onde decorria um evento que envolvia a construção e utilização de um instrumento para medir a distância às estrelas. Prestando-se o Ministro a ser interpelado pelos alunos, um deles avançou com a seguinte pergunta: "Para que é que isto serve?". É fácil imaginar que o Sr. Ministro tenha respirado fundo, antes de ter avançado com uma resposta construtiva: "Olha, serve por exemplo para aprenderes a medir; aqui estás a medir a distância às estrelas, noutras circunstâncias medirás outras coisas, mas há princípios da medição que são comuns a todas as medições e que podes aprender com esta actividade". Não se sabe se o miúdo terá retido o ensinamento, mas é bem provável que sim, pois não é todos os dias, nem é toda a gente que tem acesso pessoal a um ministro, seja ele da Ciência ou de outra pasta, e dele recebe ensinamentos úteis e sábios.

\section{Medir SEJA o QUe for}

Era o último exame de Licenciatura em Ciências Físico-Químicas; tal como acontecia à generalidade dos alunos, era o exame oral da disciplina de Óptica. O Professor tinha por hábito começar o exame com uma "pergunta de algibeira", sobre assunto que, obviamente, não cons-

mfcamoes@fc.ul.pt tava de forma explícita nas Folhas. A reacção do aluno à pergunta introdutória e a qualidade da resposta condicionava irremediavelmente o modo como a oral iria decorrer e, com isso, o resultado final; pelo menos a forte correlação entre ambos assim o dava a entender. Uma delas foi: "Quando se faz uma medição de uma grandeza, seja ela qual for, de facto, na prática mede-se sempre a mesma grandeza; qual é essa grandeza?"; pensando em diversos aparelhos de medida imaginando o acto de ler a intensidade do sinal medido, fosse ele qual fosse, e imaginando uma escala com um ponteiro ao longo da qual se movimenta e cuja deflexão, maior ou menor, corresponde ao valor medido da grandeza, o aluno respondeu: "um comprimento". A resposta poderia ter sido melhor, mas o Professor deu-se por satisfeito e a oral foi um sucesso. Do que a seguir se tratou não ficou registo na memória, a não ser vagamente que meteu Transformadas de Fourier. Embora à primeira vista o parecesse, a questão não era irrelevante e continha o mérito de fazer entender a essência de uma calibração!

\section{De PEQUENINo É QUe SE APRENDE A MEDIR}

Em 1989, o então recém-eleito Presidente da Divisão de Indústria da britânica Royal Society of Chemistry, RSC, apresentava-se aos mais de onze mil associados, em vésperas da celebração do $148^{\circ}$ aniversário da RSC. Fazia-o começando por invocar as suas reminiscências da Escola e em particular da sua primeira aula de Química cerca de 50 anos antes, que nunca mais esquecera. A atracção que a Química lhe tinha despertado resultava do fascinante envolvimento desta ciência com tantas facetas da vida do dia-a-dia.

Nesse dia "...Trinta e seis rapazes amontoavam-se em redor da bancada das demonstrações laboratoriais, cada um agarrando pela primeira vez um tubo de ensaio. Ouviram da boca do professor a seguinte indicação

"Encham o tubo com água até meio e mostrem-mo..."

Um por um, os alunos iam-se aproximando, mostravam o tubo e ouviam uma ou a outra das duas sentenças

"Qual é o teu nome?... Ficas de castigo sem ires ao recreio!"

"E o teu nome é como?...Tu podes ir para o recreio!"

A princípio, a atribuição do castigo parecia-lhe arbitrária, mas de repente, percebeu! Olhou rapidamente para o seu tubo e depressa concluiu que não ia escapar! Olhou de seguida para o colega do lado e, vendo que também ele não iria ao recreio, sem demoras o convenceu que lhe podia vender a correcção do erro e com isso o direito de ambos irem ao recreio! É que o seu tubo estava bastante mais de meio, enquanto o do colega ficava cá muito por baixo.... Meio cheio era mesmo meio cheio, caso contrário... não havia recreio!

Naquela primeira lição tinha aprendido vários ensinamentos importantes. Aprendera como é importante prestar atenção às instruções e segui-las cuidadosamente. Aprenderam a medir 
rigorosamente. Aprendera... Aprendera... Até aprendera a lei da oferta e da procura ...".

Mas se medir volumes é uma operação unitária que os químicos executam sistematicamente, muitas são as operações e medições de outras grandezas a que recorrem frequentemente, como é o caso da pesagem para avaliação de massas, na base da generalidade dos estudos científicos e de grande relevância metrológica.

\section{Metrologia científica e Metrologia legal}

Antoine Lavoisier, é reconhecido como o Pai da Química por ter introduzido o método científico no estudo quantitativo dos sistemas materiais, através do uso da balança e das determinações de variações de massa que ocorriam durante as transformações a que eram submetidos. Curiosamente, foi também Lavoisier o proponente e grande impulsionador do Sistema Métrico Decimal na época da Revolução Francesa. A unidade padrão de massa proposta pela academia francesa foi o grama, g, tendo, a 22 de Junho de 1799, sido depositados nos Arquivos da República em Paris, dois padrões de platina representando respectivamente $o$ metro e o quilograma, no que foi um dos primeiros passos para o desenvolvimento do Sistema Internacional de Unidades, SI. A situação em França condicionou a adesão dos países, que olhavam para a questão como um gesto de apoio ou de oposição política. Cerca de um século mais tarde, a 20 de Maio de 1875, dezassete países assinaram a Convenção do Metro (A República Portuguesa assinou em 1876; o número de adesões tem crescido, sendo 51 Países membros e 24 Países associados, a 10 de Setembro de 2007) que criou o BIPM (Bureau International des Poids et des Mesures), território internacional, em Sèvres, nos arredores de Paris. Foram criados novos protótipos e, em 28 de Setembro de 1889, foram enviadas cópias para os países signatários. Para Portugal, onde reinava D. Maria II, foram distribuídos o Protótipo $\mathrm{n}^{\circ} 10$ do Metro Padrão, confiado à

Comissão dos Trabalhos Geodésicos Topográficos e Hidrográficos do Reino, actualmente entregue à responsabilidade do IGP (Instituto Geográfico Português) e o Padrão Nacional da Massa, cópia $n^{\circ} 69$ do Protótipo Internacional, à guarda do Laboratório de Massa do IPQ (Instituto Português de Qualidade).

Vigorava até então, em Portugal, o sistema legal de Medidas de Peso e de Capacidade estabelecido por D. Manuel I em 1500. Com uma longa e rica história sobre as medidas de peso e capacidade em Portugal e no resto da Europa [1], o sistema de metrologia legal português estabelecido por D. Manuel I tentou harmonizar as várias medidas que com a mesma designação tinham valores consideravelmente diferentes. O Marco Padrão Manuelino, Fig. 1, foi construído em 1499 sendo constituído por massas marcadas de bronze que encaixam dentro umas das outras até à maior que funciona como caixa de todas, pesando tanto como a soma das outras, uma por uma cada com massa metade da seguinte e todas juntas pesando o dobro da maior.

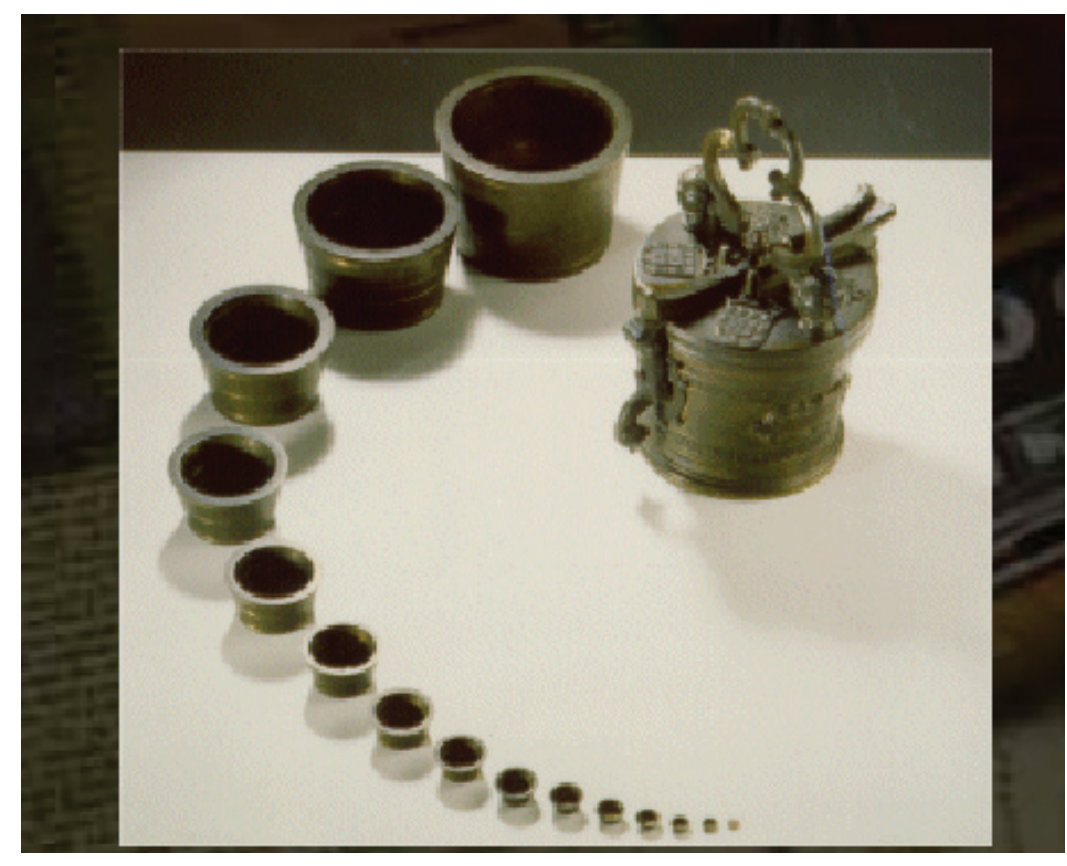

Figura 1 Marco Padrão Manuelino

Réplicas foram distribuídas pelo País, construindo a pirâmide das medições, rastreáveis desde a base com as pesagens de rotina em trocas comerciais, até ao topo da qualidade metrológica, ocupado pelo padrão primário. O Marco Manuelino, equivalente a $229,5 \mathrm{~g}$, subdividia-se em 16 onças e estas ainda em grãos (1 gr $\approx 0,05 \mathrm{~g}$ ) destinados fundamentalmente a pesar ouro e prata. Múltiplos do Marco eram usados para pesagem de produtos de menor valor comercial, designadamente cereais. Dois marcos perfazem um arrátel, $459 \mathrm{~g}$, que é para Portugal o equivalente à Libra Inglesa. Em valor de massa crescente eram usuais a Arroba e o Quintal. Os padrões secundários do Arrátel conhecidos, que terão na altura sido distribuídos pelo País, têm massas que, avaliadas recentemente, variam entre 452,0 g (Évora) e 459,5 g (Lisboa), o que é ainda uma variação considerável, tornando a comparabilidade de resultados de pesagens em instituições de várias localidades pouco credível.

A definição e a estabilidade de unidades de medição são do maior interesse público a todos os níveis, do meramente comercial ao científico, garantindo a rastreabilidade que permite a comparabilidade dos resultados das medições. No topo da pirâmide metrológica para as medições de 
em 1983 foi redefinido relativamente a uma constante física fundamental, a velocidade de propagação da luz no vácuo, $\mathrm{c}_{0}$, (o metro, $\mathrm{m}$, é o comprimento do trajecto percorrido pela luz, no vácuo, no tempo de 1/299792458 do segundo) a definição do quilograma é a de um objecto convencional, o protótipo internacional do quilograma (um cilindro de 39 milímetros de diâmetro e de altura, feito de uma liga de $90 \%$ de platina e $10 \%$ de irídio, construído com massa igual à de 1 litro de água desmineralizada, à temperatura da sua densidade máxima, $4^{\circ} \mathrm{C}$ ).
Neste período de cerca de 100 anos, a massa do padrão primário internacional tinha diminuído cerca de $50 \mu \mathrm{g}$ relativamente à média dos padrões nacionais supostamente idênticos, o que aponta para a necessidade de redefinir o kg. Embora variações desta ordem de grandeza não se reflictam na generalidade das operações, elas são relevantes sob o ponto de vista fundamental, pelo que prosseguem estudos com o objectivo de acordar uma nova definição que obedeça a requisitos de fácil compreensão, baseada em leis físicas consensualmente aceites, consistente com a

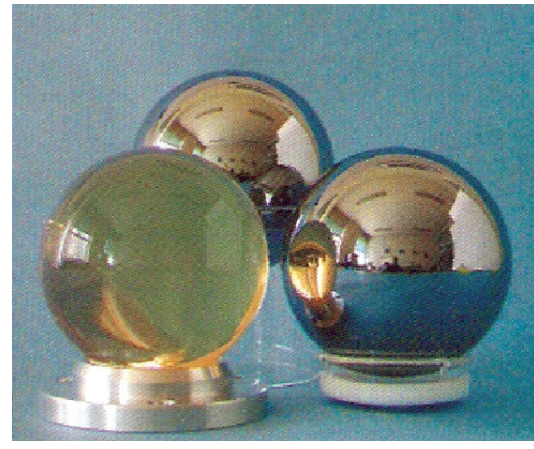

Figura 4 Cristal de silício, com número de átomos e volume bem determinados, candidato a referência do kg padrão, comparado com duas esferas análogas feitas em prata

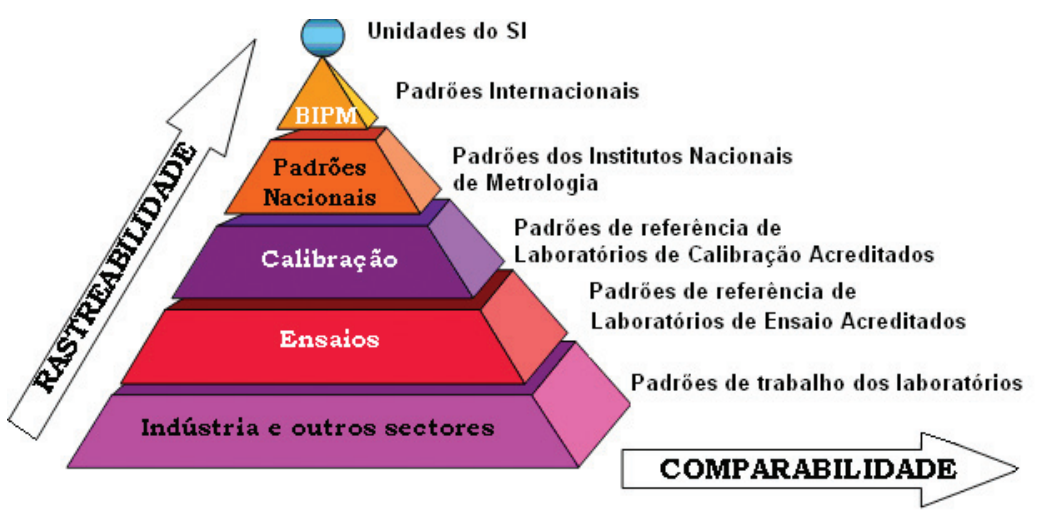

Figura 2 Hierarquia do sistema metrológico

Depositado no BIPM desde 1889, Fig. 3, juntamente com mais 6 cópias, fechados com três chaves diferentes na mão de pessoas distintas, a verificação das cópias nacionais relativamente ao padrão internacional [2], levada a cabo entre 1988 e 1992, revelou alterações, tal como já tinha também sido observado para o metro-padrão.

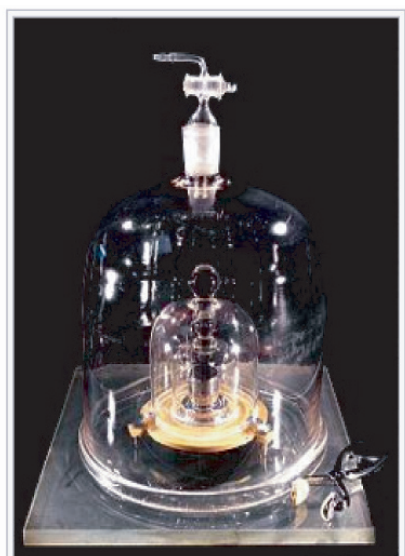

Figura 3 Padrão de $1 \mathrm{~kg}$, feito de uma liga de platina e irídio, depositado no BIPM, em França definição anterior e com as restantes unidades SI e com possibilidade de ser materializada num padrão estável, de fácil reprodução, com um valor de incerteza preferencialmente inferior ao verificado anteriormente [3]. Tendo em mente a meta de 2011, estão em curso experiências que visam associar a definição do $\mathrm{kg}$ à constante de Planck, $h$, e à constante de Avogadro, $N_{\mathrm{A}}$. Para garantir massa constante, como alternativa para o padrão de platina, apresenta-se como referência viável uma esfera de $1 \mathrm{~kg}$ de silício, $\mathrm{Si}$, com volume bem determinado, feita com um número definido de átomos. Num projecto internacional de colaboração entre o BIPM e cientistas da Rússia, da Alemanha, da Itália, da Bélgica, do Japão, dos Estados Unidos da América e da Austrália, foi criado um cristal de silício que se encontra em Sidney, na Austrália, para onde foi enviado para acabamento e avaliação (ver Fig. 4).

\section{REFERÊNCIAS}

[1] Luís Seabra Lopes, "Sistemas Legais de Medidas de Peso e Capacidade, do Condado Portucalense ao Século XVI", Portugália, Nova Série, vol. XXIV, FL/ Univ. Porto, (2003) 113-164.

[2] G. Girard, "The Third Periodic Verification of National Prototypes of the Kilogram (1988-1992)" Metrologia 31 (1994) 317-336.

[3] P. Becker, P. de Bièvre, et al. "Considerations on future redefinitions of the kilogram, the mole and of other units", Metrologia 44 (2007) 1-14. 


\section{$6^{\text {th }}$ \\ International \\ Vanadium Symposium}

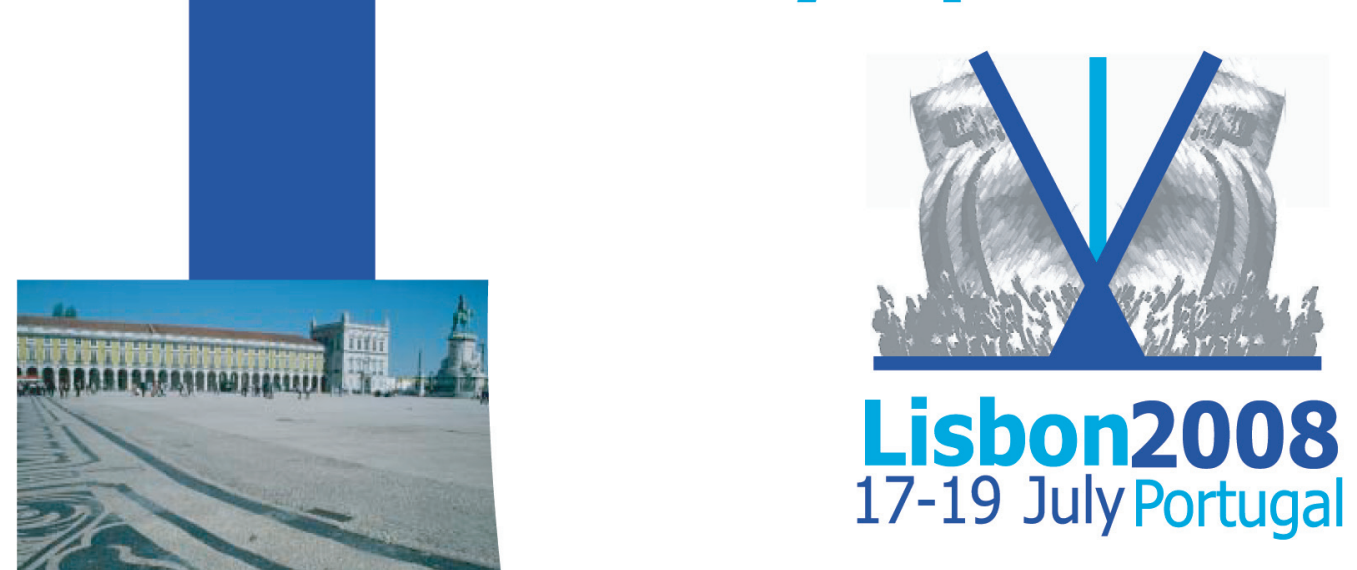

\section{THE CHEMISTRY AND BIOLOGICAL CHEMISTRY OF VANADIUM}

w w w. va n a d i $\mathbf{w}$ s i x.co m

\section{Organizing Committee}

João Costa Pessoa (Chair)

joao.pessoa@mail.ist.utl.pt

Hitoshi Michibata (Co-chair)

hmichi@sci.hiroshima-u.ac.jp

Kan Kanamori (Co-chair)

kanamori@sci.u-toyama.ac.jp

Secretariat

Centro de Química Estrutural, Instituto Superior

Técnico, TU Lisbon

Av. Rovisco Pais, 1049-001 Lisbon, Portugal v6@spq.pt
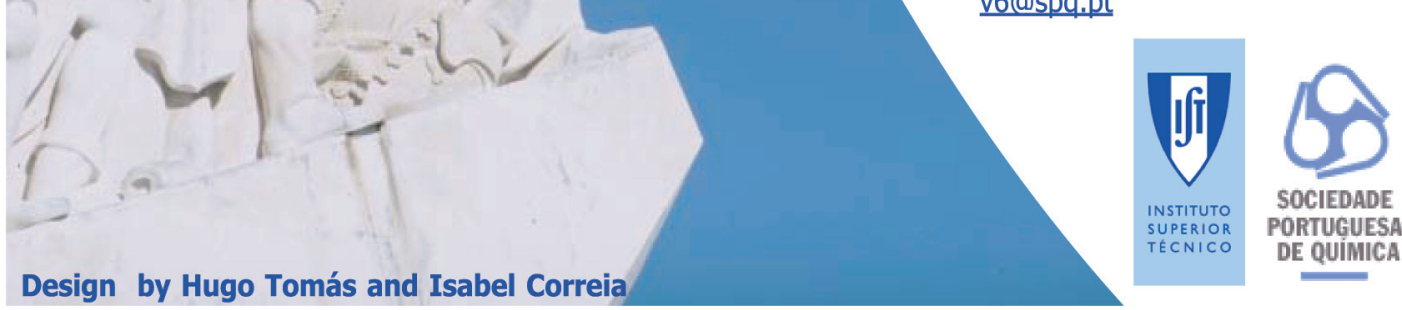

FCT DE QUimica 